\title{
AC 2011-2132: APPLICATION OF SYSTEM SELECTION TOOL TO TRAF- FIC CONGESTION IN METRO ATLANTA: A CASE STUDY
}

\section{Adeel Khalid, Southern Polytechnic State University}

Dr. Adeel Khalid is an Assistant Professor of Systems Engineering at Southern Polytechnic State University (SPSU) in Marietta, Georgia USA. His expertise include Multidisciplinary design and optimization of Aerospace systems. He has worked as systems engineer at Avidyne Corporation. The company manufactures glass cockpits for general aviation aircraft. Dr. Khalid was involved in architecture definition, design and development of cockpit avionics. He is experienced in test case scripting, verification and validation of Primary Flight Display (PFD) and Multi-Functional Display (MFD) applications. He is adept in performing requirements definition, analysis, review, management, and documentation using Dynamic Object Oriented Requirements Software (DOORS). As a lead systems engineer, he played an instrumental role in designing, developing, and testing the next generation of Entegra Electronic Flight Instrument System (EFIS).

Dr. Khalid received his Ph.D. in Aerospace Engineering from Georgia Institute of Technology. He holds Master of Science degrees in the discipline of Mechanical Engineering from Michigan State University, and Industrial, and Aerospace Engineering from Georgia Institute of Technology. He obtained Bachelors of Science degree in Mechanical Engineering from Ghulam Ishaq Khan Institute. His academic background is notable for a strong emphasis on research and teaching. As a researcher at Georgia Tech, he worked on system design of Aerospace vehicles. His research is focused on system level design optimization and integration of disciplinary analyses. Dr. Khalid has held the positions of adjunct professor at Lahore University of Management Sciences (LUMS) and SPSU. He has also worked as postdoctoral fellow at Georgia Tech.

\section{Chyna Kristin Vaughn}




\title{
Application of System Selection tool to Traffic Congestion in Metro Atlanta: A Case Study
}

\begin{abstract}
Traffic and congestion is a problem in most major U.S. cities. The difference between traffic in Atlanta compared to New York or Los Angeles is the lack of proper planning and budget to meet the transportation demands of a continuously growing city. Over the past few decades, population and traffic congestion in Metro Atlanta has continuously been on the rise. The problem has been exacerbated with a dwindling budget to support current and future transportation projects and initiatives. The Georgia Department of Transportation must become open to additional ways to resolve this problem. This paper reviews the past, current and future transportation concerns, and analyzes several transportation alternatives based on Systems Engineering comparative analysis. We illustrates that the most effective and highly desirable solution to Metro Atlanta's transportation problem is the development and implementation of a Specialized HOV lane. Past and recent survey data highlight the key selection criteria for the utilization of an alternate method of transportation. This paper is a case study to demonstrate the application of systems engineering tools and methodologies acquired in a systems engineering graduate program.
\end{abstract}

Systems Engineering Methodology

This study is an example of the application of the systems engineering methodology. The process as shown in Figure 1 is a generic process taught as part of the systems engineering graduate level curriculum. This helps students understand and embed the efficient processes and procedures into real world problems. Students are tasked to pick a few tools and use them to address a real life problem. The tools used in this study include requirements analysis, conformance, architecture development, and standards identification, use case analysis, analysis of alternatives and others. This process encourages learning the implementation of systems engineering in an educational environment. This technique of educating students not only helps them learn and retain the material, but it also helps address important issues. It provides a broad systems perspective to domain specific problems.

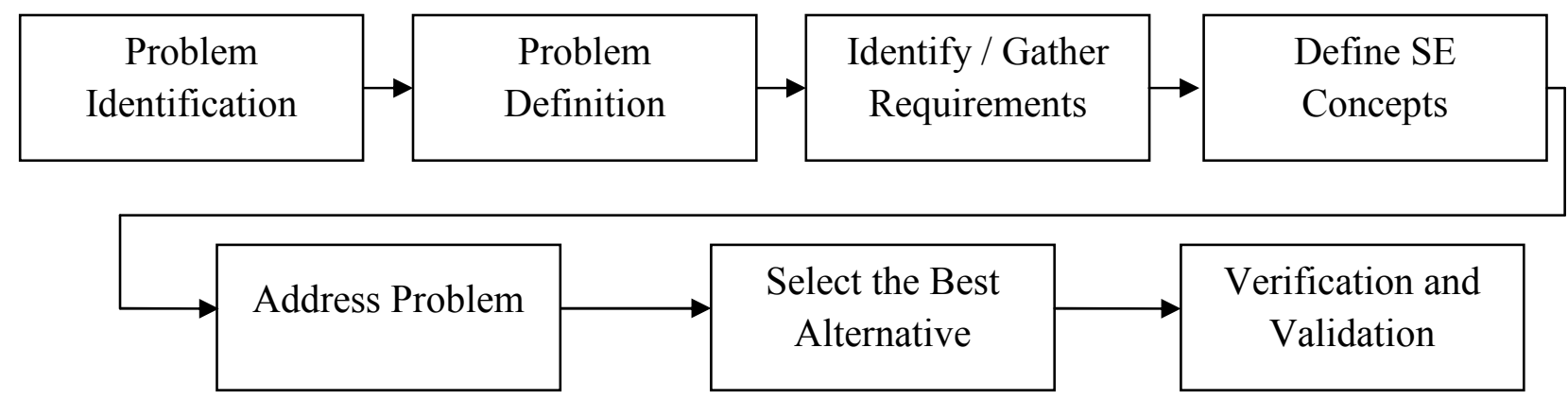

Figure 1: Systems Engineering Process 
The general intent of this study is to demonstrate the students' knowledge of the integrative aspects of systems engineering process. The work performed draws upon skills and knowledge acquired in the SE program.

Introduction and Literature Review

According to the Chamber of Commerce ${ }^{1}$, Atlanta, Georgia is one of the fastest growing cities in the US. Per 2009 data, 3,813,700 people reside within the 10-county metropolitan region of Atlanta. The growth evident from the fact that "Over the past six years, the metro area has added more than 142,000 people annually, more than any other <city $>$ in the United States."1 Noting the large population change in the Atlanta Metropolitan area, the Center for Urban Transportation Research (CUTR) ${ }^{2,12}$ analyzed the original development plans for communities in 1950 relative to today; recognizing the emphasis in the establishment of car oriented community development ${ }^{2}$. There are various reasons for this rapid population growth including reasonable cost of living, weather, industry diversity and industry growth. While a growing population has its advantages such as increased revenue, there are also some disadvantages such as over population and heavy traffic patterns. Since many business and recreation/entertainment venues are located within a small proximity of downtown Atlanta, a large flux of residents crowd the major highways and interstates each day. Due to the cost of living and the limited availability of homes within a short distance to downtown, a large number of commuters from surrounding counties sit in traffic for extended periods of time, to and from their residences. This vehicle congestion not only increases travel time for commuters, but it also contributes to the deterioration of highways and major streets. It results in unsafe driving conditions and increased vehicle collisions and moving violations. According to data retrieved from the 2000 Household Travel Survey, the establishment of various handheld technical systems to record Travel Diaries can assist in determining issues within the metro area. This is done by tracking transportation activity across several Georgia counties ${ }^{3,4}$. Prior to the development of this new technology, in 2003 The Road Information Program (TRIP) ${ }^{5,6,7}$ conducted a surveying study to determine which areas of metro Atlanta yield the largest costs due to traffic congestion focusing on commuter travel time and fuel dollars spent. Noting the success of this study, TRIP ${ }^{5}$ conducted a similar study on congestion while also producing key travel points across the state where transportation budget should be spent for congestion reduction. While the studies that TRIP has conducted are very helpful, The Victoria Transport Policy Institute ${ }^{9}$ believes the focus should be on key congestion points across the state. Data should be collected and evaluated based on vehicle miles traveled (VMT). Reduction goals should be established to assist in the resolution of transportation concerns ${ }^{9,13}$. Traffic within Metro Atlanta is a key concern for many people, namely residents, commuters, tourists and potential transplants (individuals or families considering relocating). In an attempt to alleviate and/or eliminate some of these concerns, a traffic study has been conducted by the authors to determine which areas contained within Metro Atlanta would provide the biggest return on investment in regards to public transportation overhaul. The main objective of this study is to reduce traffic in a southern city with continuous inhabitant growth. This serves as a case study for the implementation of Systems Engineering tools and methodologies learnt in a graduate program. A similar study completed by the Reason Foundation in 2006 yielded traffic congestion in Atlanta, GA to be the number one priority for the city in order to maintain stability and productivity, for without mobility there is no 
productivity ${ }^{16}$. Alongside productivity, reducing traffic within Metro Atlanta can also provide the following major benefits:

- Increase revenue for city of Atlanta

- Increase tourism of downtown Atlanta

- Decrease in congestion

- Preparation for future anticipated growth

- Ability to Go Green! - Decreasing smog and air pollution

- Decrease in motor vehicle collisions and personal moving violations

- Decrease the amount of time for transportation systems in and through the city (18wheelers, commercial trains, etc) to meet their destination points

- Save and increase Department of Transportation (DOT) jobs

- Decrease state taxes due to increased revenue

In order for Metro Atlanta to reap some of the previously mentioned benefits, additional alternatives of transportation must be provided for the majority commuting population in an effort to alleviate congestion and increase safety. Georgia Department of Transportation (GDOT) and the American Association of State Highway and Transportation Officials (AASHTO) highlight the expansion of current systems. This includes additional HOV or controlled highway lanes, which will quickly resolve many traffic concerns ${ }^{10}$. Graduate students at Georgia Institute of Technology have proven through their study that employers should be required to create a more flexible work environment to limit roadway travel ${ }^{21}$. This paper reviews the current state of transportation within Metro Atlanta, analyzes potential alternatives to transportation and provides a recommendation towards the development and implementation of the best-fit solution. A number of systems engineering tools acquired are applied to address a large problem. This study serves to demonstrate that the tools and methods acquired in the graduate program can be applied successfully to address large scale systems problems.

Problem Identification

Atlanta has come a long way from the railway city it originally was established. "It was born as a railroad settlement of saloons at the end of the line from Chattanooga, TN... when it was incorporated it changed its name from Terminus to Marthasville and eventually to Atlanta."13 Several historians remember the origination of the name Atlanta in different ways. Some say the name Atlanta came from the middle name of a residing politician's daughter, Atlanta, while others say that its name signified the "end of the Atlantic railroad." 8,17 Regardless of name origin, one thing was clear, Atlanta was and still is a prosperous city to live in. But why Atlanta; what makes Atlanta the city to relocate to? During the 1950s and 1960s...Atlanta Chamber of Commerce adopted a slogan and proclaimed Atlanta as "the world's next great city and later it became the first city to advertise itself to the rest of the country as a good place to do business, a practice that quickly became commonplace." $14,15,18$ Aside from "southern hospitality" shared amongst residents and visitors, "one of Atlanta's most endearing qualities is its weather..." "From the turn of the century, Atlanta has continued to attract people who eventually adopt the city as their own." 8 This continuous growth over the past fifty years has changed the demographics of city. Figure 2 provides a graphical interpretation of Atlanta and its surrounding counties $^{20}$. Metropolitan Atlanta will refer to those counties surrounding the I-285 perimeter 
highway. Downtown Atlanta is located inside of the I-285 perimeter at the cross section of I-85 and I-75.

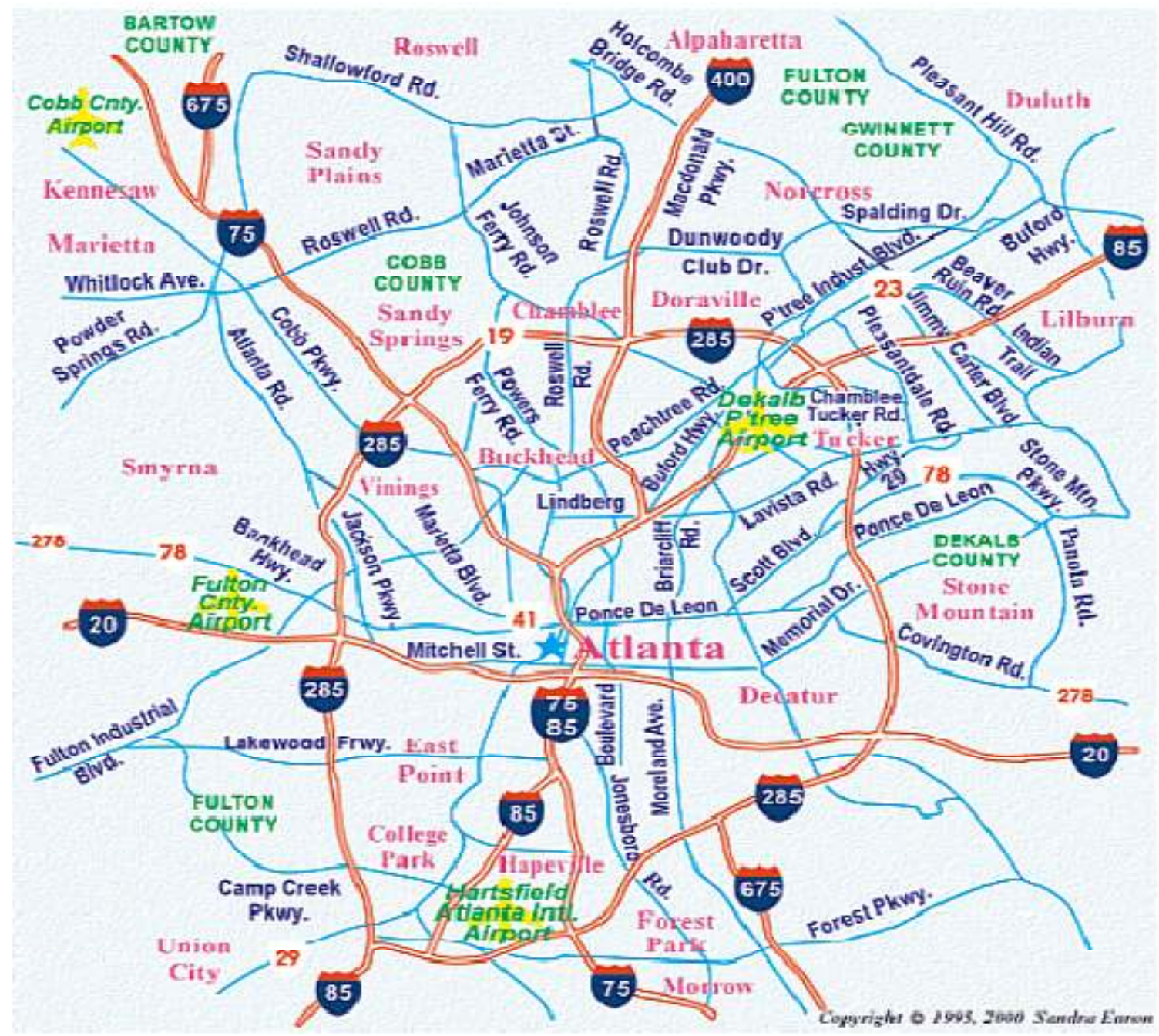

Figure 2: Atlanta, Georgia County Map ${ }^{20}$

As new residents continue to flock to this city of the south, many other changes inevitable of a large city occur as well. Increases in industry create additional jobs and new markets of employment. As industry grows, the employment for additional, highly qualified candidates is also required thereby forcing a continuous growth within the city and the city limits. As stated earlier, Atlanta was not originally built to be a large metropolitan city. So many people argue that the architects and transportation engineers in the past did not consider ways to build a city for large future growth. Due to the large influx of residents to date, the GDOT, the Regional Railway Association (RRA) and the U.S. Department of Transportation (DOT) have to determine ways to work with the current city structure and population demands to establish effective transportation for residents as well as commuters through the city of Atlanta. As many other large cities in the world, increased population directly correlates with increased transportation requirements through the city limits. As Atlanta continues to thrive as a large city in the south-eastern U.S., individuals and families continue to relocate or visit the city as a tourist 
each year. "Traffic is horrific during rush hour and only marginally bearable the rest of the time - a fact of life that's beginning to influence people's decisions about where to live." 8 The focus of this research is to highlight ways in which traffic congestion in Atlanta can be reduced or eliminated. Instead of focusing on a specific day or time that will make the largest impact, this paper will review all options. The authors hope to determine the best solution for implementation. The Metro Atlanta Chamber of Commerce (MAC) spends a large sum of its operating budget reviewing the current status of the area while also conducting research on future growth ${ }^{1}$. It depicts, as Georgia's population reaches 13.6 million by 2035, the Metro Atlanta region will reach a population of almost 7 million by 2030 . This growth to 7 million is about a $65 \%$ increase in population from 2000 . It proves that Georgia is the third-fastest growing state and metro Atlanta is the fastest growing region. Atlanta is ranked 49th in the nation with respect to per capita transportation spending. This basically means past spending of Georgia's and specifically Atlanta's transportation budgets is vastly behind the requirements of the population $^{1}$. In order to prepare the city of Atlanta for the future influx of residents, the GDOT completed the projects listed in Table $1^{8}$.

Table 1: Past Transportation construction in Metro Atlanta

\begin{tabular}{|l|l|l|}
\hline \multicolumn{1}{|c|}{ When? } & Constuction of I-285 perimeter highway & $\begin{array}{l}\text { Reduce city traffic by offering a means to travel to } \\
\text { opposite sides of the city without going through } \\
\text { downtown Atlanta }\end{array}$ \\
\hline 1960 s & $\begin{array}{l}\text { Widening of I-85 and I-75 north and south of } \\
\text { downtown Atlanta }\end{array}$ & $\begin{array}{l}\text { Increase in population and commuters to and through } \\
\text { downtown Atlanta; additional travel lanes on major } \\
\text { lighways out of the city would reduce traffic } \\
\text { congestion }\end{array}$ \\
\hline 1990 s late & $\begin{array}{l}\text { Construction of GA-400 N from downtown } \\
\text { Atlanta to Forsyth County }\end{array}$ & $\begin{array}{l}\text { Increase in population and commuters that reside } \\
\text { north of city limits. Additional highway going } \\
\text { northbound would allow for industry expansion and } \\
\text { remove traffic congestion from major roadways } \\
\text { going same direction. }\end{array}$ \\
\hline 1990 s late & $\begin{array}{l}\text { Addition of High Occupancy Vehicle (HOV) } \\
\text { Lanes to I-75 and I-85 }\end{array}$ & $\begin{array}{l}\text { Increase in population and commuter traffic. Limited } \\
\text { land to allow for additional lane expansion near city } \\
\text { limits. Establish a carpool lanc to cncourage } \\
\text { commuters to park and ride and reduce number of } \\
\text { vehicles on major roadways. }\end{array}$
\end{tabular}

As years past, the GDOT realized additional transportation projects were required to be put into place in order to reduce the traffic congestions problems in Metro Atlanta and other surrounding counties. The details regarding regulation on transportation and transportation funding requests for the state of GA are shown in table 2. 
Table 2: Georgia Transportation Bills ${ }^{9}$

\begin{tabular}{|c|c|c|}
\hline When? & What? & Why? \\
\hline 2007 & House Bill 434 & $\begin{array}{l}\text { Metro Atlanta Chamber proposed a measure that would } \\
\text { allow two or more counties to voluntarily form transportation } \\
\text { regions anywhere in the state and bring a list of projects } \\
\text { along with up to a } 1 \% \text { sales tax to fund those projects to the } \\
\text { votes in the region for approval. }\end{array}$ \\
\hline 2008 & $\begin{array}{c}\text { Senate Bill } 845 \& \text { House Bill } \\
1035\end{array}$ & $\begin{array}{l}\text { Get Georgia Moving proposed a measure that would allow } \\
\text { predefined multi-county regional commissions to call a } \\
\text { referendum on a list of transportation projects along with } \\
\text { sales tax to fund them. }\end{array}$ \\
\hline 2009 & $\begin{array}{c}\text { Senate Resolution } 44 \& \\
\text { Senate Bill } 39\end{array}$ & $\begin{array}{l}\text { Senate offered a measure that would create a pre-defined } 10 \text { - } \\
\text { county metro Atlanta region, and allow for a flexible, single } \\
\text { county or voluntary multi-county region option outside the } \\
\text { metro area. }\end{array}$ \\
\hline 2009 & House Bill 277 & $\begin{array}{l}\text { House Transportation Committee Chair representative Vance } \\
\text { Smith offered a list of transportation projects set in statute } \\
\text { that would be funded by a } 1 \% \text { statewide sales tax. }\end{array}$ \\
\hline
\end{tabular}

While these projects assisted in decreasing the traffic congestion issues during the years that they were created, they were not long-term fixes to resolving transportation concerns in a continuously growing southern city. In order to provide the best solution to the problem, additional research to address that root cause needs to be conducted.

\section{Problem Definition}

Several indicators are provided in the past regarding the benefits for determining ways to reduce traffic and congestion in Metro Atlanta. Based on the research report by the Metro Atlanta Chamber of Commerce, following are the key facts that relay the importance of reducing traffic congestion problems in Metro Atlanta ${ }^{1}$ :

- Metro Atlanta drivers spend a total of over 56 hours per year sitting in traffic; the 3rd worst delay nationally

- Congestion costs the metro Atlanta region almost $\$ 3$ billion per year; the $4^{\text {th }}$ largest cost in the nation

- Vehicle miles travelled (VMT) will increase by almost 78\% from 1990 to 2020

While some drastic changes have been made to the transportation systems within metropolitan Atlanta, additional changes must be implemented in order to maintain a healthy way of life for area residents. These prospective changes would serve as resolutions to the presenting problem. There are several ways that the results of traffic congestion can be alleviated. The first way to reduce traffic congestion is to remove the emotional impact traffic has on the individual. Regardless of light, medium or heavy traffic, negative emotions about the transportation environment will have a negative impact on the current situation. The second way to reduce traffic congestion is to provide alternate methods of transportation. While alternative methods of transportation do not reduce the volume of individuals commuting from one place to another, it can potentially consolidate the number of vehicles required to transport the same number of 
people, thus reducing the amount of traffic. The third and final way to reduce traffic congestion is by removing the requirement to travel at all. This relates to an overall reduction of the number of individuals that are required to commute anyplace and heavily relies on technology to fill the void of a person to be required in a specific location at a specific time. Each of these ways to reduce traffic congestion, emotion, alternatives and reduction are explained in further detail in the following section.

\section{Emotional \& Mental Connection}

The human brain is a powerful force. It is the engine that drives our bodies day in and day out. Some functions of the brain are logical, such as continuously blinking all day to keep pupils from drying out while other functions of the brain are illogical or based on emotion, such as freight or happiness. David Maister, an expert in the psychology of queuing, talks about a series of propositions regarding waiting in line and the mental affect traffic congestion has on drivers and passengers $^{19}$. In review of these propositions, it is important to note that not all of his propositions highlight the impact the brain and emotions have on traffic congestion. Each proposition has an imaginative scenario tied to it to assist in illustrating its derivation.

Proposition \#1: Unoccupied time feels longer than occupied time - Engagement in a conversation with a passenger or family member on a cellular phone mentally decreases the amount of time for travel between point $\mathrm{A}$ and $\mathrm{B}$.

Proposition \#2: Anxiety makes waits seem longer - The distance between point A and B seems longer when the driver has to use the restroom, is late for an appointment or is low on gas.

Proposition \#3: Uncertain waits are longer than known, finite waits - The first time travelling from point A to B seems to take a longer than the return trip from B to A, after driver is familiar with surroundings. Also, waiting at traffic signals with time changing indicators (walk/don't walk or numerical countdown) assists in preparing the driver to wait, thus waiting does not seem as long.

Proposition \#4: Unexplained waits are longer than explained waits - When an accident can be acknowledged ahead, driver establishes a cause to wait and is more patient, however when no cause for slow traffic is in sight, driver is stressed over the unknown.

Proposition \#5: Unfair waits are longer than equitable waits - Driver gets anxious when other lanes are able to move and their lane is not. However if all lanes move at the same slow speed, or move in equal adjustments over a span of time, driver is more patient with waiting. Consider a moving freeway versus a car required to stop at a stoplight to gain access to the freeway from the on-ramp.

While Maister's propositions may not be valid for all drivers, most drivers do exert a certain level of stress based on their emotional reaction to current traffic conditions. Specifically in slow moving traffic, drivers continue to have a sense of urgency to reach their final destination, causing a false sense of hope in various methods to "beat" the traffic congestion such as lane changing. 
According to the National Highway Traffic Safety Administration, 10 percent of vehicle collisions occur due to lane changing ${ }^{19}$. Therefore, decreasing the amount of lane changes would decrease the number of roadway and highway collisions, which would therefore decrease the traffic congestion caused from the accidents. Traffic jams and congestion is like an accordion: As traffic slows in a jam, it compresses; as congestion eases, the accordion "opens" and cars begin to speed up. Because of the uneven nature of stop and go traffic, these shifts happen in different lanes at different times ${ }^{19}$. So, although a driver may feel they are getting closer to their destination faster, the idea is he or she is simply buying their time in the traffic just like everyone else, while also increasing their probability of causing or participating in an accident. Consider the following situation: A Canadian television news program had two different drivers commute along the same route on a highway at the same time. One was told to make as many lane changes as possible, the other to avoid changing lanes. The chronic lane changer saved a mere four minutes out of an eighty-minute drive, which seems hardly worth it. The stress involved in making all those lane changes probably took more than four minutes off the driver's life ${ }^{19}$. The fact that drivers experience more losses than gains while driving in congestion plays perfectly into a well-known psychological theory called "loss version." ${ }^{19}$ While in theory it would be helpful to establish tools to assist drivers in alleviating key stress factors in the commuting world, the truth is, there is no one solution to resolving stress for all drivers. Instead of focusing on the mental state of traffic congestion, this paper analyzes the ways to physically reduce the number of drivers required to be on the road at any given time, thus reducing traffic congestion.

\section{Vehicle Reduction}

Many Atlanta Metro residents get into their vehicles each morning, drive to work, spend all day in the office and proceed to drive home once the day ends. If a resident was not required to complete their daily tasks at a location different from where they reside, they would essentially be removed from the commuting population, thus decreasing traffic congestion. There are several ways in which industry can affect traffic congestion through the development and implementation of programs that support work/life balance such as flexible work schedules, telecommuting or tele-working, virtual employment opportunities and virtual meetings. Flexible work schedules would allow employees to work hours other than the typical workday schedule. This will help to reduce the number of people required to travel during the hours noted as "rush hour" in the mornings and evenings. Instead of an employee having a typical work day of 8am$4 \mathrm{pm}$ or $9 \mathrm{am}-5 \mathrm{pm}$, an employee would have the option of arriving anywhere between $4 \mathrm{am}$ and departing as late as 8pm as long as they are present during the job's indicated core work hours (such as $11 \mathrm{am}-3 \mathrm{pm}$ ). Telecommuting or tele-working would allow employees to work from an alternate location with access to company network. This will reduce the number of individuals required to travel to work on certain days of the week. Many employees have secure internet connections at home, which would allow them to work from a home office when provided a company asset (laptop or home personal computer) to complete tasks on. Many employees who telecommute comment that they work more hours when telecommuting than in the office due to limited disruptions and little to no commute time to their office desk. Virtual jobs are very similar to telecommuting except company would hire full time employees that are able to work a large portion of their job from their home or a location other than the office site. Similar to telecommuters, employees with virtual jobs would be provided a company asset to complete 
their jobs at the remote location. Virtual meetings allow employees from other states who would add to residential commuter traffic can attend meetings virtually through the use of televisions, cameras and microphones. This will reduce the number of additional nonresident commuters on the roads. Although many of the work/life balance employer options above would assist in resolving some traffic concerns, all workers are not able to take advantage of such programs due to the nature of their job or their position. While it would be great to assume if all workers who had the ability to reduce commuting time, could, residents would still have a requirement to travel to and from at some point, illustrating that other options must be considered. "Virtually since traffic congestion began, plans have been put forward to stagger work schedules so that everyone is not on the roads at the same time, but even today, with telecommuting and flextime, traffic congestion persists because having a shared window of time during which we can easily interact with one another still seems the best way to conduct business."19 While reducing emotional stress related to traffic congestion and implementing work life balance programs at major employers may assist in reducing commuter traffic, additional measures must be taken in order to make an impact on the current situation. This paper focuses on the method of reducing congestion traffic in Atlanta, by first determining the root cause of the problem, soliciting feedback for preferences and determining the best solution based on highest return on investment.

\section{Financial Concerns}

In order to start any project, funding has to be allocated from a provided budget. The GDOT is responsible for establishing a Transportation Plan every five years. The recommendations are consistent with the State's transportation mission that focuses on maintenance of the system, safety, mobility, economic development and environmental quality ${ }^{11}$. A review of the 2001-2025 GDOT Transportation plan, provides insight into past, current and future budget allocations, as well as policy changes that would affect how transportation projects are prioritized within the state of Georgia. "Revenue available to fund GDOT's 2025 plan, under current policies, is estimated at $\$ 36$ billion over the 25 -year time period ${ }^{11}$. This is neither enough to finance programs that DOT has already committed to, nor those that have been identified as needed to address future transportation demands. Due to the current budget setbacks for transportation programs, "Georgia is reliant on the fuel tax to raise revenue for transportation investments. Georgia raises $93 \%$ of its transportation revenue from the fuel tax compared to an average of $60 \%$ in other states." 11 Acknowledging that decrease in fuel consumption directly affects the bottom line of the transportation budget puts another perspective on the best solutions to resolving traffic congestion. To gain a better understanding of the transportation budget for Georgia and how it works, "the major source of transportation funds are derived from the taxes on motor fuel. This is also commonly referred to as a user tax, because only those who use motor fuel tax pay the tax." 11 Only making those who consume motor fuel contribute to the transportation budget does not align with future budget allocation strategies. If the end goal is to reduce the number of vehicles required to consume motor fuel, then the budget will continue to decrease, causing the heavily used methods of transportation to require additional upkeep. Another method of funding transportation projects is required in order to ensure that all the needs of the state, and especially in Metro Atlanta, are considered and prioritized. It is true that "major investments in all modes of transportation will be needed to maintain mobility of the citizens of Georgia. Due to the lack of adequate funding, there will be deterioration in current levels of 
system performance, including pavement quality, average speed and accidents." ${ }^{11}$ Since the scope of any additional projects will impact the overall budget, alternatives in this research focus on customer driven ideal solution, instead of budget friendly alternatives.

\section{Root Cause Analysis}

Besides the finances and budget allocation concerns, there are other concerns that need to be mentioned. These concerns are provided from those that are directly impacted by the traffic congestion in Atlanta, its residents. Every few years the GDOT conducts the Atlanta Regional Commuter Survey over the phone ${ }^{11}$, in cooperation with the U.S. Department of Transportation. The survey results depicted in Table 3 are from the 2007 respondents, which included a random sample of 4,000 workers residing in the 20 -county nonattainment region of Atlanta. The survey takers were 45 percent male, and 55 percent female. 93 percent of survey takers were between the ages of 25-64 years.

Table 3: Motivation for using commute alternatives (in percentages)

\begin{tabular}{|c|c|c|c|}
\hline Survey Question & High & Medium & Low \\
\hline You believe use of alternative modes would contribute to reduced traffic congestion & 65 & 12 & 23 \\
\hline You believe use of alternative modes would improve air quality & 63 & 14 & 23 \\
\hline You believe air pollutants from Vehicle Emissions contributes to Global Warming & 56 & 13 & 31 \\
\hline $\begin{array}{l}\text { You or a loved one develops a health condition, such as asthma, related to poor air } \\
\text { quality }\end{array}$ & 47 & 15 & 38 \\
\hline $\begin{array}{l}\text { Employer allows you to work from home occasionally on a day you are regularly } \\
\text { assigned to travel to work }\end{array}$ & 49 & 6 & 45 \\
\hline $\begin{array}{l}\text { Employer allows you to start work earlier or later than you do today, making it easier } \\
\text { to arrange a carpool schedule or ride transit }\end{array}$ & 36 & 12 & 52 \\
\hline $\begin{array}{l}\text { A guaranteed ride home (GRH) in case of an unscheduled event on days you do not } \\
\text { drive alone to work }\end{array}$ & 54 & 15 & 31 \\
\hline $\begin{array}{l}\text { Pre-tax payroll deduction option to cover vanpool and or transit costs of up to } \$ 105 \\
\text { per month }\end{array}$ & 53 & 16 & 32 \\
\hline Travel lanes reserved for carpools, vanpools and buses on major highways & 47 & 14 & 39 \\
\hline Monthly gas card worth $\$ 40$ for 3-person carpools & 44 & 17 & 39 \\
\hline $\begin{array}{l}\$ 3 \text { per day for a three month period to switch from driving alone to another type of } \\
\text { transportation for travel to work }\end{array}$ & 38 & 19 & 43 \\
\hline A discounted or free pass for public transit & 38 & 13 & 49 \\
\hline $\begin{array}{l}\text { A list of people who live and work near you whom you could contact for carpooling } \\
\text { and vanpooling }\end{array}$ & 34 & 20 & 46 \\
\hline Priority, reserved parking at work for carpool and/or vanpools & 34 & 13 & 53 \\
\hline $\begin{array}{l}\text { A chance to win a monthly drawing for a } \$ 25 \text { gift certificate if you do not drive alone } \\
\text { to work and it you report these days online in that month }\end{array}$ & 24 & 15 & 61 \\
\hline
\end{tabular}

Key items to note from Table 3 are that although commuters realize that the use of alternate methods of transportation will assist in reducing traffic congestion and is better for the environment, commuters still like the flexibility to utilizing their own personal vehicles for transportation throughout the Metro Atlanta area. Saving money or monetary incentives are not enough to persuade commuters to utilize any alternate mode of transportation. Digging a little deeper into the survey may provide additional answers to this de-motivation. The following other key findings were noted from the survey and are key to the determination of alternatives to reduce traffic congestion: 
- $77 \%$ stated that no bus or train operators offered services they could use to travel to and from work

- $40 \%$ work at locations in or near a Transportation Management Association (TMA) service area.

- $35 \%$ work along or near a major arterial route (I-85North Corridor, I-75 North Corridor, and SR-400 Corridor)

- $62 \%$ of respondents gave the Atlanta region a low rating for ease of getting around without a car

- $69 \%$ of respondents gave the Atlanta area a low performance rating for traffic congestion

- $82 \%$ of respondents claimed that a more congested route is the primary reason for a more difficult trip

Given this additional survey information it is reasonable to infer that a large percentage of commuters work near a major highway. They are unable to utilize alternate modes of transportation due to the lack of access to a terminal at the start or end of commute. This indicates even if commuters wanted to take advantage of public transportation options, the inability or inconvenience of use would deter them from considering the option further. Since the GDOT survey results are slightly dated, we conducted a survey to ensure the feelings of residents were still the same. 2010 survey respondents consist of 45 Metro Atlanta residents between the ages of 16 and 65 with 49 percent male and 51 percent female. Key findings include the following:

- Figure 3 shows a graphical interpretation of the convenience of current public transportation to the typical commuter. These transportation options are within 7 miles of residence. Similar to the GDOT survey, commuters are still unable to take advantage of public transportation options due to the limited availability within close proximity to their homes.

- Survey results showing the consideration of use of alternate modes of transportation are shown in Figure 4. Note that commuters are most interested in the utilization of a HOV lane, suggesting they are still interested in maintaining use of their own personal vehicles. Note that the least favorite option is the public bus, which signifies less freedom of start and end commute times as well as route taken to destination. There is also a privacy consideration when comparing the least favorite to the most desired.

- Convenient factors to consider with alternate modes of transportation are shown in Figure 5. These key Factors in Alternative Modes of Transportation provide insight into the most important to least important factors when considering the development and implementation of alternate modes of transportation. Note that the most important factor is convenience to arrival location, with speed to destination and frequency of availability close behind. These three main factors speak to the importance of flexibility and versatility within a mode of transportation. Commuters would like the feel of having more control, even when using public transportation. The least important factors are capacity and discounts. Commuters are more interested in getting to their destination on time and in close proximity than riding with others or getting a discount. 


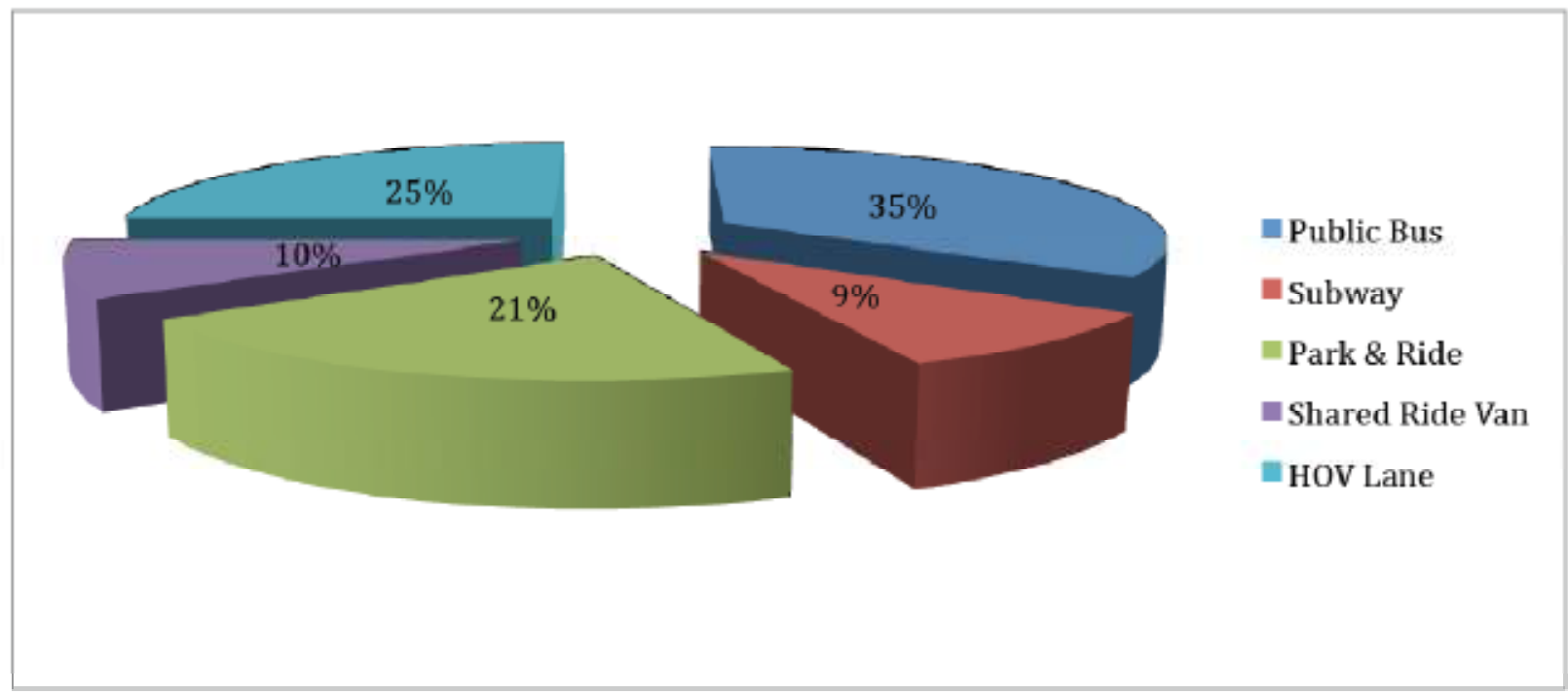

Figure 3: Transportation options within 7 miles of residence

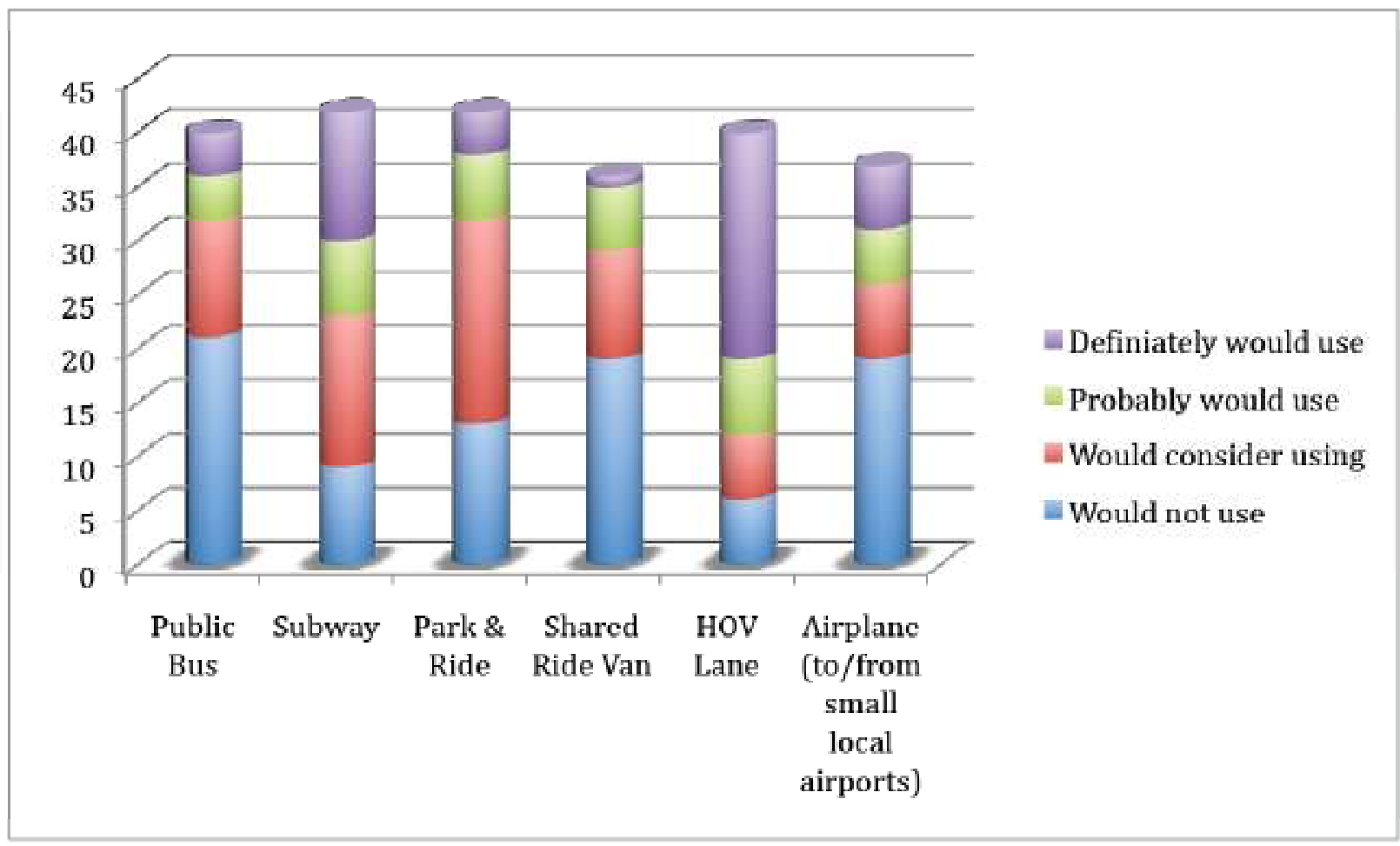

Figure 4: Alternative transportation interest

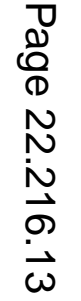




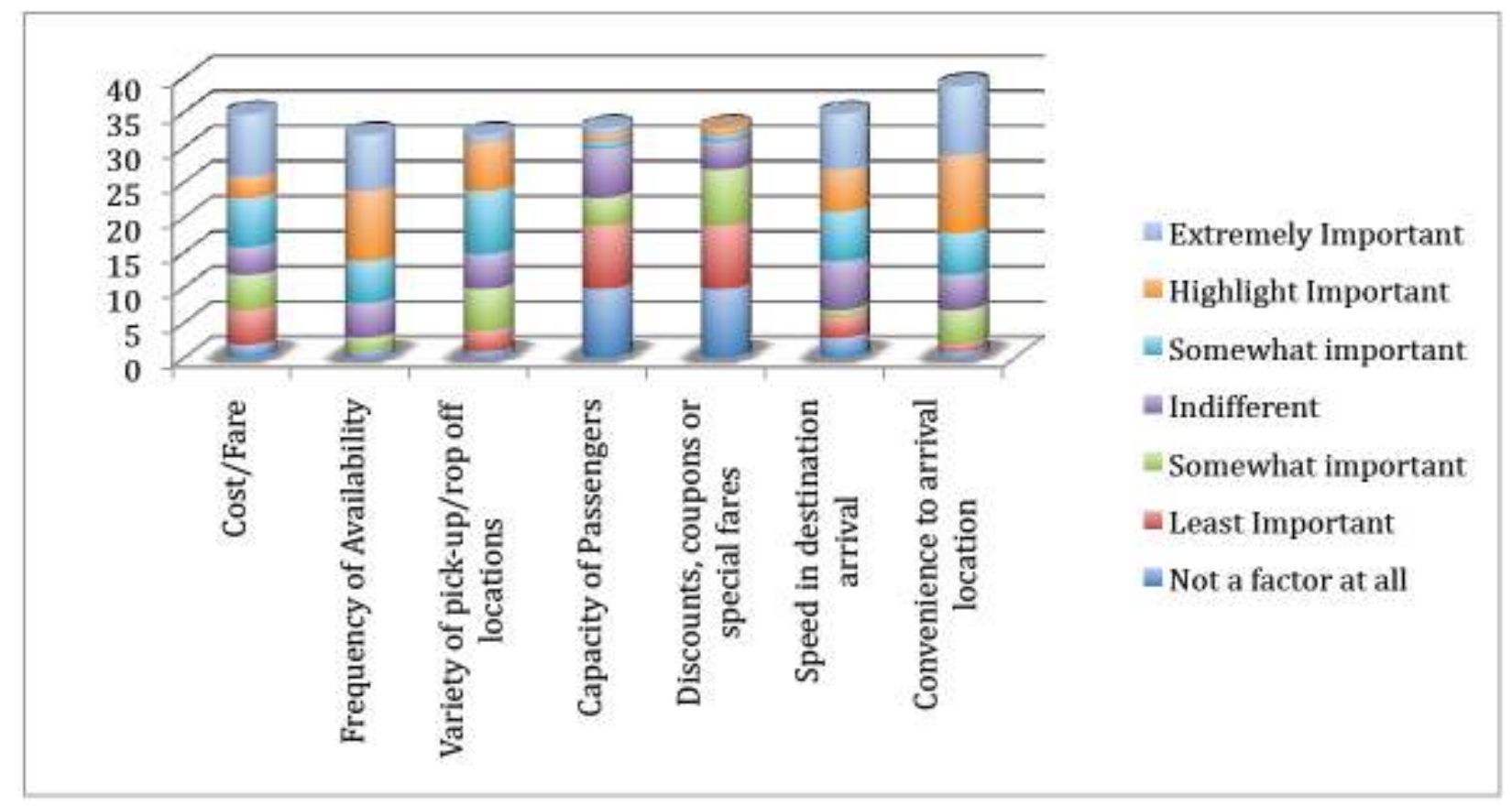

Figure 5: Key factors in alternative modes of transportation

The following other key findings were noted from the survey and are important in the determination of alternatives to reducing traffic congestion:

- "If public transportation, i.e. Marta was more accessible outside the perimeter that would help traffic."

- "Surrounding counties public transportation needs to respond to one another."

- "They should have express lane instead of HOV lanes. These express lanes will allow people to enter at a certain location and only exit every 7 to 10 miles. These HOV lanes are a waste of tax payers' dollars...they have not decreased the traffic problems."

- "Offer incentives to those who utilize the GA Transportation System on a frequent basis. Target a more Eco-Friendly environment. Expand on current MARTA lines."

- “...the State-wide system utilizing of toll roads and limited access to highways complement the existing Interstate Highways."

These additional comments by survey respondents align with the high demand for HOV lanes and usage. A majority of those surveyed are most interested in utilizing the current system in different ways to assist in decreasing traffic congestion. By utilizing information provided in these surveys, a variety of alternatives are reviewed and analyzed to determine which alternative will meet the needs of the typical Metro Atlanta commuter, while maximizing future potential through limited finance resource allocation.

Alternatives for Consideration 
After careful consideration of previous transportation developments, current traffic congestion problems and commuters' desires, the following alternatives are reviewed for development and implementation.

- Airplane Bus

- Bullet Train

- Bus HOV

- Bus Integration

- Subway Addition I-75

- Subway Expansion I-85

- Specialized Lane - Toll

- Truck HOV - Toll

Pros and cons of these alternatives are discussed in Table 4. Each option is explained in detail with positive and negative feedback regarding its development and implementation. 
Table 4: Pros and Cons of Alternatives

\begin{tabular}{|c|c|c|c|}
\hline Alternative & Brief Description & Pros & Cons \\
\hline Airplane Bus & $\begin{array}{l}\text { Individuals who own small personal jets can } \\
\text { provide transportation to neighboring small } \\
\text { airports. }\end{array}$ & $\begin{array}{l}\text { Helps those who } \\
\text { commute long } \\
\text { distances to cut out } \\
\text { travel time } \\
\text { Decrease number of } \\
\text { personal vehicles on } \\
\text { the road }\end{array}$ & $\begin{array}{ll}\text { - } & \text { Expensive to use as a } \\
\text { consumer } \\
\text { - Reliant on personal jet } \\
\text { availability } \\
\text { - Distance from airports } \\
\text { to final destination } \\
\text { - Commuting from } \\
\text { airport to final } \\
\text { destination }\end{array}$ \\
\hline Bullet Train & $\begin{array}{l}\text { A bullet train is similar to the look and feel of } \\
\text { a typical subway, however it makes little to no } \\
\text { stops within the city limits. The bullet train } \\
\text { will service areas surrounding the perimeter, } \\
\text { and will have only a few stops once in the } \\
\text { perimeter. This option is a fast shuttle from the } \\
\text { furthest point s of town. } 30 \text { minute ride from } \\
\text { Peachtree city to Hamilton } \\
\text { Mill/Braselton/Chateau Elan }\end{array}$ & $\begin{array}{l}\text { Speed from origination } \\
\text { to destination } \\
\text { Passenger volume }\end{array}$ & $\begin{array}{l}\text { - Not useful for intercity } \\
\text { commuting } \\
\text { Tracks will need to be } \\
\text { built to accommodate } \\
\text { train to outermost } \\
\text { residential areas }\end{array}$ \\
\hline Bus HOV & $\begin{array}{l}\text { Specified lane on the highway will be } \\
\text { available for the use of commuter buses and } \\
\text { shared ride vans. Specific days and times can } \\
\text { be applied to lane usage. }\end{array}$ & $\begin{array}{l}\text { Promotes car-pooling } \\
\text { Inexpensive cost to } \\
\text { ride }\end{array}$ & $\begin{array}{l}\text { - Bus needs to reach } \\
\text { large residential areas } \\
\text { Smog from buses } \\
\text { polluting area } \\
\text { Buses only lane does } \\
\text { not help single riding } \\
\text { commuters }\end{array}$ \\
\hline Bus Integration & $\begin{array}{l}\text { Each county within Metro Atlanta and its } \\
\text { surround counties have a public bus system. } \\
\text { Some buses provide transfers between other } \\
\text { counties and some only provide }\end{array}$ & $\begin{array}{l}\text { - Ability to lean a } \\
\text { current process } \\
\text { Increase bus usage } \\
\text { across counties }\end{array}$ & $\begin{array}{ll} & \text { Long commute time } \\
\text { - } & \text { Limited seating } \\
\text { Smog from buses } \\
\text { polluting area }\end{array}$ \\
\hline $\begin{array}{l}\text { Subway Expansion } \\
\text { I-85 }\end{array}$ & $\begin{array}{l}\text { Current subway ends at the perimeter } \\
\text { connection around the city (where I- } 85 \text { meets } \\
285 \text { ). Subway expansion would add additional } \\
\text { subway tracks in the center of northbound and } \\
\text { southbound I-85 to end of HOV lane } \\
\text { (northbound - Duluth an southbound) }\end{array}$ & $\begin{array}{ll}\text { - Increased commuter } \\
\text { pool } \\
\text { - Current technology - } \\
\text { just expansion } \\
\text { - Inexpensive cost to } \\
\text { ride } \\
\text { Space exists between } \\
\text { northbound and } \\
\text { southbound }\end{array}$ & $\begin{array}{l}\text { Time to expand } \\
\text { Additional construction } \\
\text { problems will add to } \\
\text { congestion }\end{array}$ \\
\hline $\begin{array}{l}\text { Subway Addition } \\
\text { I-75 }\end{array}$ & $\begin{array}{l}\text { Subway will be created that will run in } \\
\text { between northbound and southbound I- } 75 \text {. } \\
\text { Subway would start in Cherokee County and } \\
\text { end in Clayton County. }\end{array}$ & $\begin{array}{ll}\text { Increase commuter } \\
\text { pool } \\
\text { Inexpensive to ride }\end{array}$ & $\begin{array}{l}\text { - Time to build since } \\
\text { subway lines do not } \\
\text { currently exist on this } \\
\text { route }\end{array}$ \\
\hline $\begin{array}{l}\text { Specialized Lane- } \\
\text { Toll Lane }\end{array}$ & $\begin{array}{l}\text { Specialized lane is an HOV lane with } \\
\text { revolving requirements. Lame is dedicated to } \\
\text { specific commuting traffic depending on } \\
\text { congestion pattern. Digital signs will be posted } \\
\text { at entrances indicating what commuter type is } \\
\text { allowed within the lane at specific period of } \\
\text { time. }\end{array}$ & $\begin{array}{l}\text { Gives the flexibility to } \\
\text { change lane admission } \\
\text { based on traffic flow. } \\
\text { i.e. if a lot of trucks } \\
\text { are present, make it } \\
\text { trucks only. } \\
\text { Monetary payback to } \\
\text { GA }\end{array}$ & $\begin{array}{l}\text { - Confusing for users; } \\
\text { lack of consistency } \\
\text { might increase number } \\
\text { of collisions } \\
\text { Will only assist } \\
\text { identified pool of } \\
\text { drivers }\end{array}$ \\
\hline $\begin{array}{l}\text { Truck HOV - Toll } \\
\text { Lane }\end{array}$ & $\begin{array}{l}\text { Specified lane on the highway will be } \\
\text { available for the use of large trucks passing } \\
\text { through the city. }\end{array}$ & $\begin{array}{l}\text { - Monetary payback to } \\
\text { GA } \\
\text { Encourages economic } \\
\text { growth in GA by } \\
\text { catering to freight } \\
\text { movement to and } \\
\text { through city }\end{array}$ & $\begin{array}{ll}\text { - } & \text { Bus needs to reach } \\
\text { large residential areas } \\
\text { Smog from buses } \\
\text { polluting area } \\
\text { Truck only lane does } \\
\text { not provide an alternate } \\
\text { method of } \\
\text { transportation for } \\
\text { commuters }\end{array}$ \\
\hline
\end{tabular}




\section{Comparative Analysis of Alternatives}

Noting the above alternative methods of transportation, the Technique for Order Preference by Similarity to Ideal Solution (TOPSIS) method is used to compare and contrast each alternative. The TOPSIS method helps to determine the best solution based on weights assigned to customer criterion, noted in the above survey analysis. Examples of consumer preferences include cost to ride, and speed to destination.

Based on the results from the survey conducted by the author of this report, weights for each criterion to measure each alternative are determined as shown in Table 5. These weights are based on the relative importance of each criterion as determined from the survey results and the use of Pugh matrix. Note that the varieties of pickup and drop-off locations, capacity of passengers, and discount coupons or special fares, are lumped together in the comfort factor. Also note that these weights are subjective. In other words they can change depending on the population surveyed.

Table 5: Weights for various criteria

\begin{tabular}{|c|c|c|c|c|}
\hline Cost to Ride & $\begin{array}{c}\text { Speed (Destination } \\
\text { Arrival) }\end{array}$ & $\begin{array}{c}\text { Convenience } \\
\text { at arrival } \\
\text { location }\end{array}$ & $\begin{array}{c}\text { Frequency of } \\
\text { Availability }\end{array}$ & $\begin{array}{c}\text { Comfort } \\
\text { Factor }\end{array}$ \\
\hline 0.15 & 0.2 & 0.35 & 0.25 & 0.05 \\
\hline
\end{tabular}

Alignment of each alternative with the indicated customer preferences is shown in Table 6. A positive sign $(+)$ indicates this alternative received a high rating for that particular criteria, noting the customer's complete satisfaction with meeting their needs of convenience and flexibility. A forward slash sign (/ ) indicates the alternative has both positive and negative attributes and a negative sign (-) indicates the customers dissatisfaction with the alternating being able to meet their needs.

Table 6: Alternative and Requirement Analysis

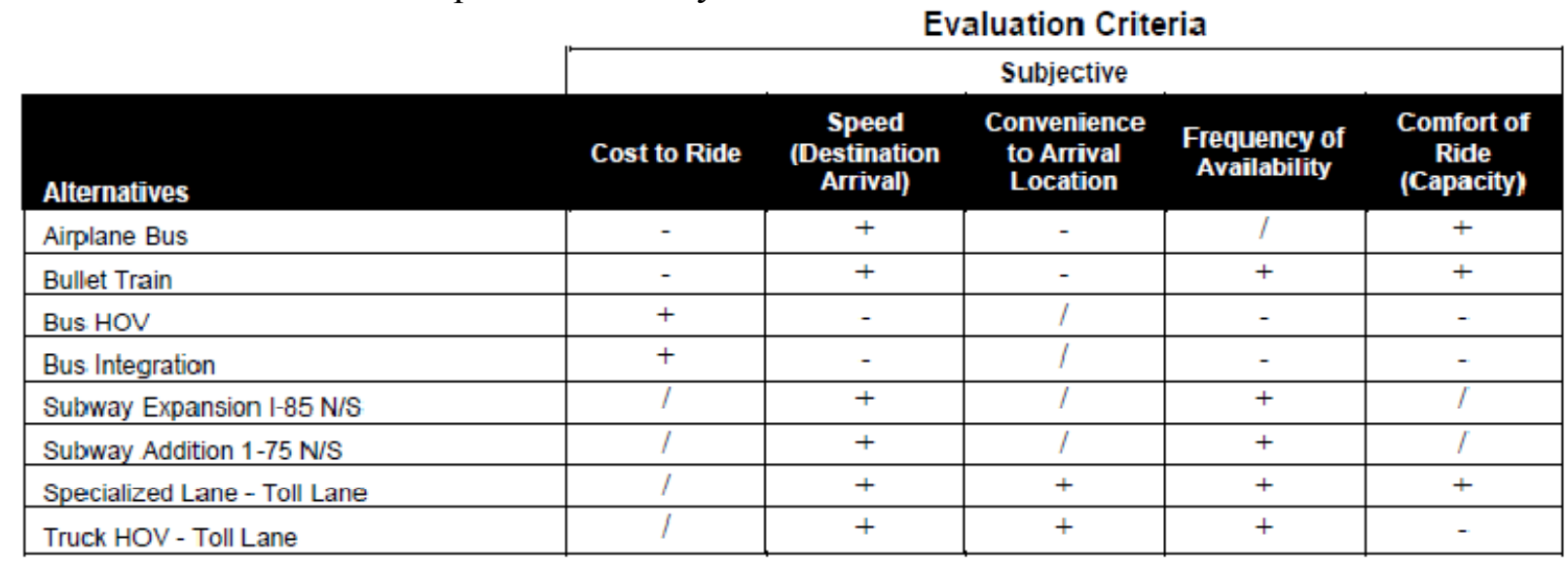

After careful evaluation of the survey results, it was determined that several key factors could be identified as objective elements, should data exist to support the alternative. To illustrate that the recommended solution will not only meet objective cost and speed demands, but also align with 
customer subjective factors, both objective and subjective analysis is included within the TOPSIS analysis. The Victoria Transport Policy Institute conducted a Cost Benefit Analysis on various modes of transportation in January $2009^{9}$. Data supporting the "Cost to Ride" factor was acquired through the use of 2007 cost per vehicle mile data, researched by alternative. Data supporting the "Speed (Destination Arrival)" factor was acquired through the use of 2007 and 2008 data highlighting the average miles per hours each vehicle will travel, noting frequent stops during peak rush hour times of the day. Objective and subjective data in support of each alternative are shown in Table 7. Note that the airplane bus alternative was not evaluated due to limited to no data. This particular alternative remains on the list, but is not a contender.

Table 7: Weight scores for alternatives

\begin{tabular}{|c|c|c|c|c|c|}
\hline & Objective & Objective & Subjective & Subjective & Subjective \\
\hline Alternatives & Cost to Ride & $\begin{array}{c}\text { Speed } \\
\text { (Destination } \\
\text { Arrival) }\end{array}$ & $\begin{array}{l}\text { Convenience } \\
\text { to Arrival } \\
\text { Location }\end{array}$ & $\begin{array}{c}\text { Frequency } \\
\text { of } \\
\text { Availability }\end{array}$ & $\begin{array}{l}\text { Comfort of } \\
\text { Ride } \\
\text { (Capacity) }\end{array}$ \\
\hline Airplane Bus & 0 & 0 & 0 & 0 & 0 \\
\hline Bullet Train & 1.682 & 30 & 3 & 7 & 11 \\
\hline Bus HOV & 16.887 & 10 & 3 & 3 & 3 \\
\hline Bus Integration & 16.887 & 10 & 3 & 3 & 3 \\
\hline Sulbway Expansion I-85 N/S & 21.842 & 24 & 3 & 11 & 7 \\
\hline Subway Addition 1-75 N/S & 21.842 & 24 & 3 & 11 & 7 \\
\hline Specialized Lane - Toll Lane & 0.382 & 32 & 11 & 11 & 11 \\
\hline Truck HOV - Toll Lane & 2.46 & 15 & 11 & 11 & 3 \\
\hline
\end{tabular}

Hypothetical positive and negative ideal solutions are defined. The positive hypothetical ideal solution is the one with the best normalized coefficient from each criterion of all the alternatives. Similarly the negative hypothetical ideal solution contains the worst characteristics normalized coefficients of each alternative. The separations of each alternative from the positive and negative ideal solutions are determined using the n-dimensional Euclidean distance.

$$
S_{i}^{+/-}=\sqrt{\sum(\text { AlternativeValue }- \text { Pos / NegIdealValue })^{2}}
$$

Relative closeness to ideal solution is determined using the closeness factor.

$$
C_{i}=\frac{S_{i}^{-}}{S_{i}^{+}+S_{i}^{-}}
$$

After several iterations to determine the best and worst scenarios in comparison with each alternative, the end result for the best alternative selection is shown in Table 8. 
Table 8: Ideal alternative selection

\begin{tabular}{|l|c|c|c|c|}
\hline Alternatives & \multicolumn{1}{c}{ Si } & Si- & Ci & Rank \\
\hline Airplane Bus & $4.27272 \mathrm{E}-10$ & 0.07755205 & 0.000000004 & $\theta$ \\
\hline Bullet Train & 0.007724435 & 0.069827615 & $\mathbf{0 . 9 0 0 3 9 6 7 6 1}$ & 2 \\
\hline Bus HQV & 0.077552045 & $9.78989 \mathrm{E}-06$ & $\mathbf{0 . 0 0 0 1 2 6 2 2}$ & 5 \\
\hline Bus Integration & 0.077552045 & $9.78989 \mathrm{E}-06$ & $\mathbf{0 . 0 0 0 1 2 6 2 2}$ & 5 \\
\hline Subway Expansion I-85 N/S & 0.100307442 & 0.022755395 & $\mathbf{0 . 1 8 4 9 0 8 7 4 4}$ & 4 \\
\hline Subway Addition 1-75 N/S & 0.100307442 & 0.022755395 & $\mathbf{0 . 1 8 4 9 0 8 7 4 4}$ & 4 \\
\hline Specialized Lane- Toll Lane & 0.001754301 & 0.075797749 & $\mathbf{0 . 9 7 7 3 7 9 0 5}$ & $\mathbf{1}$ \\
\hline Truck HOV - Toll Lane & 0.011297331 & 0.066254719 & 0.854325822 & 3 \\
\hline
\end{tabular}

While cost for manufacturing and implementation are not a factor in this evaluation, due to limited resources available, the specialized lane, as a toll lane is determined to be the quickest and easiest alternative to implement, yielding it as the best solution to resolve the current congestion problems in Metro Atlanta. The validity of this result is evident from the fact that it ties in well with the initial response received from the residents surveyed.

\section{Conclusion}

This case study illustrates an example of the use of systems engineering tools and methodologies, taught in a graduate program. Similar techniques can be used to address other large scale system problems.

Traffic congestion in Metro Atlanta is on the rise and resolving the increasing traffic congestion problem is a necessity in order to sustain a high quality of living for all of Metro Atlanta's commuting residents. The key method for determining the best solution is to ensure that adequate research is completed to thoroughly understand the current situation, questions are asked by stakeholders regarding key decision factors and implementation is transitioned smoothly from the previous method to the new method of transportation. While reducing the stresses that arise from the emotional impact of traffic and even limiting the number of vehicles traveling on the road may relieve roadway congestion, establishing a cost effective solution that aligns with key factors relative to the commuters is the key. Utilizing additional systems engineering tools to obtain specific data regarding the prioritization of key elements of alternative modes of transportation will yield the best results. Use of TOPSIS revealed that the development and implementation of a Specialized HOV lane is the solution that best meets the needs and requirements of commuters and residents within Metro Atlanta. Establishing a specialized HOV lane in Metro Atlanta would not only assist in reducing traffic congestion, but it would also be a method for the city of Atlanta and its surrounding counties to control traffic flow based on current traffic patterns. While specialized lanes are a newly considered mode of transportation, they are highly effective due to the control a city has on their use. Making the specialized lane in Atlanta a toll lane, could provide additional financial restitution for GDOT to make further improvements in other ways to reduce traffic congestion all over the state of GA. Ensuring all area drivers are familiar with the requirements and regulations of the lane is extremely important. This will help decrease the confusion and alleviate the potential increase in traffic violations and collisions due to confused drivers uneducated about the lane's usage. 
GDOT must establish an implement a training plan for all current and new drivers and ensure to include lane requirements and regulations within Driver's Education coursework and the license renewal process. Posting billboards and change board signs on the highway is another method of communicating specific lane use requirements on the spot. Despite current population concerns and transportation budget limitations, focusing on root cause analysis and the "What's in it for me" concept for Metro Atlanta commuters, enables the GDOT to implement a solution that is of interest to many without spending a large volume of manufacturing or implementation costs. While meeting the needs and interests of the Metro Atlanta commuters is key to the utilization of transportation alternatives, decreasing additional stressors and assisting in maintaining a healthy quality of life will continue to make Atlanta a prosperous southern city to welcome new residents and tourists alike.

\section{References}

1. Stockert, David. 2010 MAC Transportation Policy: Funding Metro Atlanta's Transportation Needs, Atlanta Chamber of Commerce, 2010.

2. Goodwill, J. \& Hendricks, S. Building Transit Oriented Development in Established Communities. Center for Urban Transportation Research (CUTR). Tampa, FL. November 2002. Helling, Amy. The Effect of Residential Accessibility to Employment on Men's and Women's Travel. George State University. Women's Travel Issues; Proceedings from the Second National Conference.

3. 2007 Atlanta Regional Commuter Survey, 20-County Nonattainment Area, Survey Key Findings. Georgia Department of Transportation

4. Wolf, J. ,Guensler, R. ,Washington, S. \& Lawrence, F. Use of Electronic Travel Diaries and Vehicle Instrumentation Packages in the Year 2000; TRB Transportation Research Circular E-C026 - Personal Travel: The Long and Short of It. Atlanta Regional Household Travel Survey. School of Civil and Environmental Engineering, College of Engineering and City Planning Program, College of Architecture Georgia Institute of Technology; Atlanta, GA., 2000.

5. The Road Information Program (TRIP). Georgia's Transportation Chokepoints: The Top 50 Chokepoints and Remedies for Relief. Washington D.C. April 2010.

6. The Road Information Program (TRIP). The Cost of Traffic Congestion in the Atlanta Region: The Region's 20 Worst Traffic James and The Steps Needed to Relieve Traffic Congestion. Washington D.C. May 2003.

7. Black, David. Atlanta: The Makings of a World Class City. Community Communications: Montgomery, AL. 1999.

8. Cauley, H. M. Relocating to Atlanta and Surrounding Areas. Prima Publishing: Roseville, CA. 2000.

9. Doherty, Eric \& Litman, Todd. Transportation Cost and Benefit Analysis; Techniques, Estimates and Implications, Second Edition. Victoria Transport Policy Institute. January 2009

10. Gehr, D., Lockwood, S., Maring, G., Heanue, K. \& Pisarski, A. American Association of State Highway and Transportation Officials (AASHTO). Transportation Reboot: Restarting America's Most Essential 
Operating System; The Case for Capacity: To Unlock Gridlock, Generate Jobs, Deliver Freight, and Connect Communities. April 2010.

11. Georgia Department of Transportation, 2001-2025 Transportation Plan, 2001

12. Helling, Amy. The Effect of Residential Accessibility to Employment on Men's and Women's Travel. George State University. Women's Travel Issues; Proceedings from the Second National Conference.

13. Herbert, Richard. Highways to Nowhere; The Politics of City Transportation. The Bobbs-Merrill Company, Inc.: Indianapolis, IN. 1972. Litman, Todd. Are Vehicle Travel Reduction Targets Justified? Evaluating Mobility Management Policy Objectives Such as Targets to Reduce Vehicle Miles of Travel (VMT) and Increases Use of Alternative Modes. Victoria Transport Policy Institute. May 2010

14. Mallela, J., Littleton, P., Hoffman, G., Gokhale, S., \& Ullman, G. U.S. I-85 Interchange Design- Build Project Using Prefabricated Bridge Elements in West Point, GA. Final Report. Department of Transportation/ Federal Highway Administration. November 2009

15. O’Brienm Don \& Stone, John. Atlanta. Louisiana State University Press: Baton Rouge, LA. 1994.

16. Poole, Robert. Reducing Congestion in Atlanta; A Bold New Approach to Increasing Mobility. The Reason Foundation. November 2006.

17. Rose, Michael. Atlanta, Then and Now. Thunder Bay Press: San Diego, CA. 2001.

18. Urban, C., Selman, W., Hibbard, J., Holder, G. \& Chalmers, L. Calming Neighborhood Traffic with Speed Humps: Comparing Policies and Programs in Metro Atlanta.

19. Vanderbilt, Tom. Traffic, Why We Drive the Way We Do (and What It Says About Us). Alfred A. Knoff Publishing: New York, NY. 2008.

20. VanMeter, D. D., Future of HOV in Atlanta. Technical Presentation for ASHE, Georgia Department of Transportation. October 2005.

21. Zuehlke, Kai and Randall Guensler. Employer Perceptions and Implementation of Commute Alternatives Strategies. Georgia Institute of Technology. Journal of Public Transportation, Vol. 10. November 2007

22. Website for map of Metro Atlanta - Figure 2: http://www.n-eorgia.com/atlantamap.htm

23. Survey Monkey, online survey tool. http://www.surveymonkey.com 